\title{
Qualitative Assessment of Bad News Delivery Practices during Miscarriage Diagnosis
}

\author{
Maria Brann \\ Associate Professor \\ Department of Communication Studies \\ Indiana University-Purdue University Indianapolis \\ mabrann@iupui.edu \\ Cavanaugh Hall 309 \\ 425 University Blvd. \\ Indianapolis, IN 46202 \\ 317-274-8562 \\ Jennifer J. Bute \\ Associate Professor \\ Department of Communication Studies \\ Indiana University-Purdue University Indianapolis \\ jjbute@iupui.edu \\ Cavanaugh Hall 309 \\ 425 University Blvd. \\ Indianapolis, IN 46202 \\ 317-274-2090 \\ Susanna Foxworthy Scott \\ Doctoral Student \\ Department of Communication Studies \\ Indiana University-Purdue University Indianapolis \\ sfscott@iu.edu \\ Cavanaugh Hall 309 \\ 425 University Blvd. \\ Indianapolis, IN 46202
}

This is the authors' manuscript of the work published in final form as;

Brann, M., Bute, J. J., \& Scott, S. F. (2020). Qualitative Assessment of Bad News Delivery Practices during

Miscarriage Diagnosis. Qualitative Health Research, 30(2), 258-267. https://doi.org/10.1177/1049732319874038 


\begin{abstract}
Miscarriage is one of the most common pregnancy complications health care providers discuss with patients. Previous research suggests that women's distress is compounded by ineffective communication with providers, who are usually not trained to deliver bad news effectively. The purpose of this study was to use a patient-centered approach to examine women's experiences with and perspectives of communication during a miscarriage to assist in the development of communication training tools for health care providers. During focus groups, 22 women who had experienced miscarriage discussed video-recorded standardized patient-provider interactions and recalled communication during their own miscarriages. Results of a pragmatic iterative analysis of the transcripts suggest training techniques and communication behaviors that should guide education for providers to deliver the diagnosis of and treatment options for early pregnancy loss, such as demonstrating empathy, creating space for processing, checking for understanding, and avoiding medical jargon and emotionally charged language.
\end{abstract}




\section{Qualitative Assessment of Bad News Delivery Practices during Miscarriage Diagnosis}

Miscarriage is the most common pregnancy complication with as many as $25 \%$ of pregnancies ending in a loss (American Pregnancy Association, 2017). Women who have a miscarriage often experience shock, guilt, depression, and anxiety (Adolfsson, Larsson, Wijma, \& Bertero, 2004; Hamama-Raz, Hemmendinger, \& Buchbinder, 2010; Swanson, 2000). Health care providers, particularly those working in obstetrics and gynecology (OB/GYN), should be prepared to deliver the news of miscarriage to patients (Karkowsky, Landsberger, \& Bernstein, 2016) because the way information about pregnancy loss is delivered can affect patients, by either adding to, or helping to alleviate, their distress (Bellhouse, Temple-Smith, Watson, \& Bilardi, 2018; Malacrida, 1999). Providers can assist women by handling the news with sensitivity and engaging in an informed and patient-centered dialogue to help patients navigate their coping and decision-making in the midst of a potentially confusing and unexpected loss. However, research suggests that $\mathrm{OB} / \mathrm{GYN}$ residents receive limited exposure to such interactions and might be uncomfortable engaging in delivery of bad news and providing full information about options to manage a miscarriage (Brann \& Bute, 2017; Marko et al., 2015).

Miscarriage diagnoses are emotionally laden types of diagnoses, which may contribute to this uneasiness. Because pregnancy loss is a unique form of ambiguous loss involving multiple losses (e.g., identity as parents, familial expectations, reproductive certainty; Brier, 2008; Bute \& Brann, 2015; Frost, Bradley, Levitas, Smith, \& Garcia, 2007; Hamama-Raz et al., 2010; Malacrida, 1999), providers need specific communicative strategies to aid patients when delivering this type of news. Research has demonstrated that many providers lack competence, both skills and comfort, when delivering bad news (Fallowfield \& Jenkins, 2004). So even though training models exist for delivering bad news generally, some health care providers still 
fall short when communicating with patients experiencing a miscarriage (Bellhouse et al., 2018). As such, scholars have called for improved communication skills training for providers' in the miscarriage context (Brann \& Bute, 2017). This is an important juncture of the patient-provider interaction because how bad news is delivered can impact patients long after the conversation (Brann, 2015).

\section{Patient-centered Communication}

We used a patient-centered communication framework to inform our conceptual and methodological approach in this study. Patient-centered care and communication during bad news delivery, such as in the case of pregnancy loss, can help patients make sense of what is happening and aid in developing a plan for moving forward because it is more responsive to patient needs, perspectives, and values affecting decision-making (King \& Hoppe, 2013; Mast, Kindlimann, \& Langewitz, 2005; Sparks, Villagran, Parker-Raley, \& Cunningham, 2007). More specifically, patient-centered communication includes providers' efforts to evaluate and respond to patients' understanding of the situation or diagnosis, explore patients' questions and concerns, involve the patients in the interaction, and communicate empathically (Mast et al., 2005; Sparks et al., 2007). As Sparks et al. (2007) explained, "Patient-centered communication focuses on the patient as a 'whole person' in the context of his/her psychological and social circumstances" (p. 181). Such an approach is consistent with research suggesting that the process of how health care providers deliver difficult news (i.e., how they present information, whether and how they offer

emotional support, whether they personalize their communication to each individual patient) may be even more influential on patients' evaluations of the interaction than the nature of the news itself (Munoz Sastre, Sorum, \& Mullet, 2011). Because of the significant effect patient-centered communication can have on the therapeutic, psychological, and social outcomes of a medical 
interaction, it is important for health care providers to know how to effectively communicate with a patient-centered approach.

\section{Learning to Deliver Bad News}

Research and consensus guidelines have been developed to aid providers in improving core communication skills (King \& Hoppe, 2013). Providers and providers-in-training are taught in a variety of ways including through didactic approaches; small-group discussion; small group, peer role-play; small-group, standardized patient (SP) role-play; one-to-one SP encounters; and teachable moments in clinical settings (Rosenbaum, Ferguson, \& Lobas, 2004). One technique used to assess proficiency in medical and communication skills is the Objective Structured Clinical Examination (OSCE), which involves providers visiting a rotation of stations where they perform a clinical task, often with a SP in a simulated clinical encounter, and are scored by an examiner (Newble, 2004). This type of simulation training is effective for teaching communication skills (Karkowsky et al., 2016), and research supports the use of SPs in improving bad news delivery (Olesen, Graungaard, \& Husted, 2014) and communicating empathy (Kushner, Zeiss, Feinglass, \& Yelen, 2014). It is important, therefore, to develop structured simulation-based training to assist providers in engaging in difficult conversations (e.g., miscarriage diagnosis).

Because few studies have explored bad news delivery specifically in situations involving miscarriage (Marko et al., 2015), the purpose of this study was to explore how women who have experienced miscarriage assess providers delivering news of a miscarriage to a SP in an OSCE so that this information can guide the development of educational curricula. Traditionally, content of training programs has been determined by either a consensus approach (i.e., a group of experts collaborate to decide what should be included) or a theory-driven approach (i.e., 
educators use theoretical constructs to identify key communication skills to be included;Street \& De Haes, 2013). What is typically not done is using actual patients to assess and discuss communication skills to determine best practices from their perspectives asthe ones receiving the information. This novel approach privileges the voices of women who have experienced a miscarriage, recognizing that they are experts in providing actionable feedback for clinicians to integrate into their communication instead of relying solely on a medical expert consensus or a theory-driven approach.

Previous research has shown that pregnancy loss counseling can be taught if a structured curriculum is utilized (Marko et al., 2015). However, before counseling can occur, providers need to deliver the diagnosis, which would likely also require structured communication skills training. It is essential to determine, from the perspective of patients, what communicative elements should be included in such training. By learning the perspective of women who have experienced this situation first-hand, our primary aim was to gain insight into developing tools for providers in how to communicate with a patient experiencing a miscarriage. We specifically sought to determine women's preferred communicative strategies from health care providers during a miscarriage.

\section{Methods}

\section{Design}

Forty $\mathrm{OB} / \mathrm{GYN}$ interns (i.e., first-year residents) at a medical institution in the Midwest interacted with SPs presenting as an asymptomatic 9-week pregnant woman who just had a routine ultrasound and is awaiting the results. The OSCE required providers to deliver the diagnosis of a miscarriage and discuss management options. After receiving ethics approval from the IU Office of Research Compliance (protocol \#1510381031), we selected six clips 
representing three communicative behaviors: delivering diagnosis $(M=4 \min 58 \mathrm{~s})$, explaining treatment options $(M=3 \min 30 \mathrm{~s})$, and discussing the patient's role in the decision-making process $(M=1 \mathrm{~min} 12 \mathrm{~s})$. Previous coding of the videos (see Brann \& Bute, 2017) demonstrated that all interns engaged in these three specific communication tasks. Brann and Bute selected two examples of each communicative act for participants to review to represent a range of behaviors.

A patient-centered approach to understanding best practices for delivery of bad news necessitates the privileging of patient voices (e.g., Munoz Sastre et al., 2011; Sparks et al., 2007); thus, our methodological approach included recruiting a sample of women who had personal experience with miscarriage. We conducted five focus group discussions with women who had experienced at least one miscarriage to explore their assessment of the communication in the clips and preferences for patient-provider communication about miscarriage.

\section{Participants}

We recruited women through advertisements in local newspapers, at public libraries, and on social media sites of local infant and pregnancy loss support groups. We also created a Facebook page for this study and advertised on that site. Eligible participants included women who were 18 years of age or older, had experienced a miscarriage prior to 20 weeks gestation, had sought health care during their pregnancy and/or miscarriage, and were proficient in English. Participants included 22 women between the ages of 22 and 58 years, with an average age of 36.4 years. Thirteen women had suffered multiple miscarriages (range $=2-4)$. The average time since the most recent miscarriage was 4.9 years (range $=3$ weeks-24 years) (see Table 1 for additional participant demographics). Participants received a $\$ 25$ gift card to a national retail chain for their participation.

\section{Table 1}

Demographic Characteristics for 22 Focus Group Participants 


\begin{tabular}{lll}
\hline & Frequency & $\mathbf{\%}$ \\
\hline Number of Miscarriages & & \\
\hline 1 & 9 & 41 \\
2 & 5 & 23 \\
3 & 4 & 18 \\
4 & 4 & 18 \\
\hline Race & & \\
\hline White/Caucasian & 16 & 73 \\
African American & 4 & 18 \\
Other & 2 & 9 \\
\hline Education & & \\
\hline College Degree & 21 & 95 \\
No College Degree & 1 & 5 \\
\hline
\end{tabular}

\section{Procedure}

We held focus group discussions at a local university, hospital, and library. Brann facilitated all focus groups with one other researcher attending to take notes. We audio-recorded all focus group sessions, and a professional transcriptionist transcribed each discussion. The facilitator and assistant debriefed at the conclusion of each focus group and independently wrote field notes of the discussion, which included general assessments of the focus groups and commonly discussed topics.

Participants consented to participate in the study after reading the IRB-approved study information sheet, which explained the study procedures and their rights as participants (e.g., confidentiality, study withdrawal) and included phone numbers of local psychological and support services as resources women could contact after the study. Before beginning the focus group discussion, participants completed a short demographic questionnaire. During the focus group, participants watched the six video clips of OSCE interactions and wrote notes about what the provider did well, did not do well, and how they would have felt in that scenario. We informed the participants that we would maintain the confidentiality of everything they shared and encouraged the women to also be respectful with others' private information. Then, after 
each clip, Brann led discussion about the women's perceptions of the interactions. After discussing each clip, we invited participants to share overall impressions, their own experiences, and advice they would give to providers for communicating in these situations. Having experienced a similar loss fostered an open and supportive environment for the women to discuss their own medical encounters, which lead to a thoughtful dialogue where women acknowledged and built off of each other's stories.

After the discussion, Brann informed the participants that the interactions were with a trained actor portraying a patient, and they were asked to assess realism. All participants thought the interactions were realistic and were unaware that the encounter did not involve an actual patient experiencing a miscarriage. To conclude the focus group, we thanked the women for their participation, distributed their incentive, and reminded them about the psychological services available if they experienced any distress (and a trained staff person was immediately available outside the room for the focus group that was held at the hospital).

\section{Data Analysis}

Similar to the approach used by Sparks and colleagues (2007), our analysis of the data was informed by a patient-centered approach because we focused our attention on how women evaluated the communication in the videos rather than how we, as communication researchers, evaluated the communication. Participants' assessments of the videos were informed by their past interactions during their own pregnancy loss(es). Whenever possible, we used participants' own language to label emerging themes and codes.

We used a pragmatic iterative approach to analyze the data (Tracy, 2013). Such an approach encourages scholars to move back and forth between data and conceptual frameworks (i.e., patient-centered communication) and to conduct multiple rounds of coding. Scott fact- 
checked the transcripts (Tracy, 2013) by reading the transcripts while listening to the audio files to check for accuracy and to de-identify all participants. Next, Brann and Bute engaged in an initial analysis of the transcripts in which we developed first-level (descriptive) codes, and then met to discuss emerging themes. Based on this discussion, we collapsed codes into broader second-level codes, which are codes that identify patterns in the data and include conceptual interpretation (Tracy, 2013). We then drafted a codebook of second-level codes with descriptions and exemplars for each code to use for systematic analysis among all authors. Brann tested the codebook against a subset of the data to refine the definitions and exemplars. For example, what began as "allow the patient an opportunity to respond" was refined to "create space for patients to process" as it became evident that patients discussed more than just responding but also their need to have time and space to process the information before they could craft their responses. Next, Brann trained all authors to use the codebook to analyze the transcripts. Having reached consensus on the data tested with the codebook, we were confident in the clarity of and ability to use the codebook. Therefore, Bute and Scott each coded two transcripts and Brann coded one transcript $(N=5)$. The authors met regularly to discuss data and analysis.

\section{Results}

Participants evaluated providers' communication as both effective and ineffective, and provided consistent suggestions for communicating a miscarriage diagnosis (see Table 2 for themes, communicative actions, and exemplar quotations). Specifically, they recommended providers be empathic, allow patients the opportunity to process the information, and actively check patient understanding. Additionally, they adamantly recommended that providers be mindful of the language they use and specifically suggested avoiding using medical jargon and 
emotionally charged language. This latter point may be particularly useful for clinicians in providing pragmatic and practical word-choice recommendations.

Table 2

Preferred Communication Practices when Delivering a Miscarriage Diagnosis

\begin{tabular}{|c|c|c|}
\hline Theme & Communicative Action & Exemplar Quote \\
\hline \multirow{3}{*}{ Demonstrate Empathy } & Respond to Patient Cues & $\begin{array}{l}\text { "The patient was clearly } \\
\text { distraught, and she's kind of } \\
\text { emotional and she's crying, } \\
\text { and the doctor would chime } \\
\text { in with a question here or } \\
\text { there." }\end{array}$ \\
\hline & $\begin{array}{l}\text { Provide Patients with Full } \\
\text { Attention }\end{array}$ & $\begin{array}{l}\text { "She was really listening to } \\
\text { what the patient was } \\
\text { interested in or what made } \\
\text { her feel uncomfortable and } \\
\text { kind of giving more } \\
\text { information that she sensed } \\
\text { she wanted." }\end{array}$ \\
\hline & Provide Comfort & $\begin{array}{l}\text { "She was very empathetic, } \\
\text { and her body language and } \\
\text { her voice and how she told } \\
\text { her, she's like, 'Your baby } \\
\text { has passed."” }\end{array}$ \\
\hline \multirow[b]{2}{*}{$\begin{array}{l}\text { Create Space for Patients to } \\
\text { Process }\end{array}$} & Be Silent & $\begin{array}{l}\text { "Give her a moment to think. } \\
\text { Silence is okay." }\end{array}$ \\
\hline & Avoid Rushing & $\begin{array}{l}\text { "Just the time she was taking } \\
\text { to explain it was really } \\
\text { helpful even though she'd } \\
\text { kind of already given her all } \\
\text { the information and she was } \\
\text { asking the same questions, } \\
\text { she still was being really } \\
\text { patient and giving the mom } \\
\text { the time." }\end{array}$ \\
\hline Check for Understanding & Use the Teach-Back Method & $\begin{array}{l}\text { "So what I'm hearing you say } \\
\text { is ..." }\end{array}$ \\
\hline $\begin{array}{l}\text { Avoid Medical Jargon and } \\
\text { Emotionally Charged } \\
\text { Language }\end{array}$ & Avoid the term "Abortion" & $\begin{array}{l}\text { "I don't think she needed to } \\
\text { say the word abortion. She } \\
\text { already said it was a } \\
\text { miscarriage, and I don't think } \\
\text { she needed to go into the } \\
\text { medical term of abortion." }\end{array}$ \\
\hline
\end{tabular}




\begin{tabular}{l|l|l}
\hline & $\begin{array}{l}\text { "She said something about } \\
\text { we'll remove all the parts in } \\
\text { the office, I was like, 'oh that } \\
\text { sounds really awful.' And } \\
\text { why would I want to do that } \\
\text { and-I mean it sounds like an } \\
\text { oil change or something." } \\
\text { Descriptions of Procedures }\end{array}$ \\
\hline
\end{tabular}

\section{Demonstrate Empathy}

Overwhelmingly, participants felt that the most effective communicative behavior a provider could engage in when communicating with a patient during a miscarriage is to demonstrate empathy. One participant said,

Don't act like robots.... Act like a human, act as if it was say your wife that happened to, or your daughter, or your granddaughter that it happened to. Think of if you had to talk to them in that sort of way.

Participants shared several ways that providers can show this humanness by identifying and validating patients' needs and feelings. For example, participants stated that providers could simply ask the patient what she wants to understand the unique preferences of each patient. A participant stated, "You don't know what the patient will want;" therefore, as another participant noted, "The best thing to do is ask the patient, start asking questions about your preferences so we can arrive at a solution that best meets your needs." Unfortunately, this verbal communication from the provider is often lacking; therefore, it is important for the provider to be aware of, and respond to, patients' verbal and nonverbal cues.

Respond to patient cues. Patients often make comments about their feelings or uncertainty or are visibly distraught or unsure, which is a cue to providers that they need to communicate more clearly and empathically with the patient. When a patient makes a comment about how she feels or what she needs, providers should respond appropriately. After one patient in the clip stated that she did not want to pursue one of the treatment options, the provider 
verbally recognized her feelings before moving on to another option. A participant shared, "I like how she acknowledged what the person was feeling so as soon as the patient said she didn't want to do that ... she said, 'I understand' which is, I think, better than saying, 'I'm sorry."' The participant discussed how the patient was validated by the provider's understanding instead of what might have felt like pity if the provider had simply stated that she was sorry. Although that might be the easier response, participants noted that the focus should be on the patient's needs, not on what is easier for the providers. Another participant shared an example of ineffective communication by not responding to nonverbal cues when she stated, "Having some perception about how your patient is taking that info - like clearly she was trying to block that off and there was no understanding of that." She detailed how the provider neglected to respond to the patient's nonverbal cues of "shutting down" (i.e., leaning back, putting hands over face) and did not appear to be aware of the patient's response.

Provide patients with full attention. To respond to patients' verbal and nonverbal cues, participants recognized that providers must give patients their full attention. This includes not multi-tasking (e.g., studying the patient's chart in front of her) and making sure to communicate directly with the patient (e.g., sitting eye level, making eye contact). A participant said, "When you're giving somebody bad news, set it aside, you don't need to be looking at my chart and just have a conversation one-on-one like that." Demonstrating that the provider is focused solely on the patient communicates empathy to the patient.

Provide comfort. Providing comfort, which can be accomplished both verbally and nonverbally, was also key to demonstrating empathy according to the participants. Providers must be aware of what they say in an effort to comfort patients. For instance, although providers are likely trying to provide comfort by sharing that miscarriages are a common experience and 
therefore, women are not alone, it is not always interpreted as comforting. A participant noted that discussing how common miscarriage is "devalues the experience." Likewise, another participant shared,

The "it's common" discourse, to me, is said as a way to get over this difficult piece of having to communicate this awful news and get on to the next thing. To say it's common is, for me, not a way of empathizing with the person who may be distraught in front of you.

Besides avoiding the "it's common" discourse, another way providers can offer comfort to their patients is through nonverbal communication. Many participants recognized when a provider would sit down near the patient, make eye contact, speak in a tender voice, and use supportive touch. One participant shared, "I think communicating that empathy through I think body language and tone of voice is probably the most important."

Likely because the patients were often silent for much of the interaction, participants noticed how providers responded, or did not respond, to patients' nonverbal behaviors. The silence exhibited by patients may be because they were attempting, through all the noise, to process the information, which women in our sample identified as another vital practice that providers must learn.

\section{Create Space for Patients to Process}

Because this unique form of ambiguous loss is often completely unexpected, learning of a miscarriage can be traumatic for women. According to the participants, women may need time to process the initial news of the loss and the options for managing a miscarriage. During this time of processing, participants recommended being silent and not rushing the patient or the interaction. Participants noted this particularly when a patient showed signs of being 
overwhelmed and the doctor continued to give information that might involve decision-making components. Signs of being overwhelmed included crying or clearly indicating in the interaction that they were in shock or not processing information (e.g., repeating the news of the loss as the health care provider moved forward in the conversation). This observation is particularly relevant given the increasing time constraints placed on medical encounters. Women indicated ways for providers to create this space through nonverbal communication.

Be silent. Participants were specific about providers being silent to allow women the opportunity to process. A participant shared, "When she started out, I feel like she - the doctor didn't want to leave a whole lot of room for silence. And sometimes it's okay in our, when we miscarry silence is okay, it gives us time to process." Her example illustrates the importance of providing opportunities and silence for processing. It was even suggested that providers could explain to patients the intent of the silence. Another participant said, "And even asking, 'Do you need a moment to process?' so she understands the doctor's not just staring at her; she's actually giving her that space."

Participants noticed and commented on providers talking more than listening or even just not remaining silent so the patient could process information. A participant said,

She just kept going and I'm like oh, she's just rambling and I felt like, you know, the patient was kind of trying to process it and she just kept talking. I'm like, she doesn't hear anything that you're saying. Just stop talking and let her absorb it.

Participants shared one explanation for providers not allowing time for the patient to process: they were not providing the patient with their full attention. By not reading the patient's nonverbal cues, they were unaware of the patient's need to process, but as a participant summarized, "Pretty much everybody's going to need a moment." 
Avoid rushing. Participants shared another way to make sure that patients are given this moment to process: do not rush through the conversation. One participant shared, Try really hard to not seem like you're in a rush. Making decisions when you know when you see that the doctor is rushed is hard, let alone when it's more than a cold or something, like it's not like which medicine to get. It's like life altering for that individual, like yes it happens often but if, it had never happened to me so I needed that extra slow down time.

Although miscarriages are a common pregnancy complication, it is a unique experience for the woman experiencing it. Therefore, women need time to process what is happening to their bodies and their babies.

A patient may need additional time to process the news, but beyond that, she likely will have several questions she will want answered. A participant commented on a provider who focused on the patient's need to take her time during the interaction,

She was just kind of more actively present so she just kept offering these opportunities for the mom to express what she was thinking or feeling ... she didn't try to fill a lot of the space with talking, she just kind of waited to see what the mom had to say. Participants recognized that not feeling rushed during the interaction offers women a sense of validation for her thoughts and feelings.

\section{Check for Understanding}

As many participants noted, once someone hears that they are miscarrying, they are unlikely to hear what comes next in the conversation. Thus, it is imperative that providers check the patient's understanding so that women can make informed decisions. Providers can ask the general "Do you have any questions for me? Is there anything I can answer for you?" types of 
questions as suggested by one participant, but nearly all of the participants recognized that to truly assess understanding, a more systematic approach needs to be taken.

Use the teach-back method. The technique most commonly suggested by our participants to assess understanding was to get patients to tell back the information they just heard. A participant stated, "Instead of just saying do you understand what I'm informing you of, [ask] 'Can you tell me what I just told you?' instead of just constantly, every sentence, 'Okay? Alright?"” Another participant elaborated, "Some paraphrasing and speaking back would've been really great right there." This technique for having patients explain what they were just told not only allows the provider to determine if patients heard the information but also if they understood what they heard.

\section{Avoid Using Medical Jargon and Emotionally Charged Language}

When learning about a miscarriage, patients may find it difficult to understand what is happening. This sense of confusion might be amplified when providers use medical terms that patients may not understand or that have moral or politicized associations. Because this is often a very emotional experience for women, it is also important to be sensitive to the type of language used to describe the miscarriage and how management options are performed.

Avoid the term "abortion." Although the medical terminology for a miscarriage is spontaneous abortion, this term can trigger negative connotations. A participant shared how the medical term could be emotionally charged:

She used the word abortion which for some people is very emotional and it contradictsit sounds as if it's contradicting what she said about "You did nothing wrong" because abortion sounds like a choice. It was just heartbreaking 'cause I was like well there's no part of me that chose any of this. 
None of the participants endorsed the use of the medical term abortion, and some women even commented on how hearing or seeing the word had lasting effects. For example, a participant spoke of the difficulty of seeing her pregnancy loss medically coded as an abortion and feeling judged when she had to reconcile a billing issue over the phone.

Avoid overly detailed descriptions of procedures. In addition to the medical term abortion, the language used to describe some of the management procedures was also emotionally difficult for participants. A participant said,

Some of the language she used was, I am all for medical terms, but scrape the inside of the uterus was not okay - clean out uterus. And then she said, 'Well hopefully your body will take care of it itself.' The whole take care of it. Your body is supposed to be taking care of a baby not taking care of a miscarriage you know. It was just too, not good word choices.

All participants disliked the word "scrape" to describe what happens to the uterus during surgery, and many opposed the description of "suction" when discussing a dilation and curettage (D\&C). One participant said, "She was talking about the scraping and the-I don't want to hear about that, I mean, I know that's the reality of it, but she said that at least twice," and another participant said, "I was kind of cringing because I kept worrying she was going to say the word like suck - like suction.”

Some providers struggled with what to call what was being miscarried - baby, fetal tissue, contents, or parts. Participants immediately recognized the language providers used and were very bothered by how many providers chose to describe the baby (the participants' preferred term). In each focus group, women discussed their dislike for the common term "parts." A participant said, “Especially parts 'cause then it makes you think they're going to 
disassemble my baby, it's going to get, you know, dismembered." Another participant added,

"Take out contents; remove all the parts. I'm not an assembly. Like this isn't a factory."

Providers need to be cautious about the language they use, particularly being careful to avoid using medical jargon and emotionally charged words.

\section{Discussion}

Studying bad news in the miscarriage context is especially important given that providers working in $\mathrm{OB} / \mathrm{GYN}$ frequently encounter situations where they have to share news about unexpected and potentially traumatic events (Karkowsky et al., 2016). The participants in this study did more than just assess bad news delivery, they offered recommendations based on their own expertise as women who had experienced both a miscarriage and the delivery of that bad news from a health care provider. Including patient voices is a vital tactic for improving medical education and assessment. Our patient-centered approach revealed findings that suggest a clear pattern of preferred communication practices for health care providers communicating with a patient about a miscarriage. Even with these consistent suggestions for interactions though, participants recommend that providers be mindful of the uniqueness of the situation to each patient, which is consistent with research suggesting that providers should avoid formulaic approaches to bad news delivery, especially when being patient-centered (Sparks et al., 2007). As suggested by Davies et al. (2017), "excellent care" by health care providers is authentic engagement that illustrates respect for unique situations, which requires going beyond prescribed protocols. Fallowfield and Jenkins (2004) noted,

No two patients or relatives will respond in the same way to the same news, but the way in which bad news is conveyed can substantially influence their emotions, beliefs, and attitudes towards the medical staff and how they view their future. (p. 313) 
Therefore, it is important to get patient feedback about their preferences.

Our results suggest clear implications for improved trainings of both practicing and future providers. We delineate a specific set of behaviors that could be taught to audiences using a range of teaching tools. First and foremost, providers must communicate empathically. In previous studies, bereaved parents were most appreciative of deliverers of bad news who demonstrated concern and caring instead of professional detachment (e.g., Fallowfield \& Jenkins, 2004). Although the recommendation to communicate empathically may seem obvious, health care providers are likely to see pregnancy losses so often that diagnosing a miscarriage could become routine for them. However, providers must remember that this is not a routine experience for women, and therefore, they must be mindful of how they communicate when providing care to a woman experiencing such a loss. Our findings offer specific ways that providers can demonstrate empathy (e.g., by giving their undivided attention, by not overemphasizing how common miscarriage is). Other researchers have also suggested both verbal and nonverbal ways to communicate empathy (Gair, 2012). Simple changes like allowing for pauses and silence during the conversation, using explicit "tell back" methods to check understanding (Kemp, Floyd, McCord-Duncan, \& Lang, 2008), and attending to patients' nonverbal cues can ameliorate the stress and confusion women feel when receiving such news. As noted by Morse (2011), the act of delivering bad news is only part of the process of patients knowing the diagnosis. Patients may hear the words, but the magnitude of the news may not be realized immediately. In fact, both women and men who have been told that they are having a miscarriage claim to experience shock and emotional numbing that may limit their understanding and acceptance of what is occurring (Hamama-Raz et al., 2010). This is why it is so important 
for health care providers to create space for a patient to process the information being given to better understand what was just communicated.

Although some principles, like empathy, apply across contexts, our study suggests specific recommendations that must be considered in interactions about pregnancy loss to help address this unique form of ambiguous loss and support previous work that revealed that empathy is important but is only one component of patient-centered bad news delivery (Mast et al., 2005). Other studies acknowledge that it is important for providers to use "simple language" (Marko et al., 2015) or suggest that physicians offer a "neutral response" (Wallace, Goodman, Freedman, Dalton, \& Harris, 2010), but our investigation helped to identify specific terminology and wording that should be avoided when delivering news of a miscarriage. In doing so, we reveal an important consideration that is not emphasized in other work: the importance of terminology and emotional language. Women in our study were especially attuned to the loaded and graphic language providers used to describe the medical aspects of miscarriage and management options. Although the use of jargon and specific terminology might be second nature to health care providers, women in our focus groups were troubled by vivid descriptions of "scraping" the uterus or removing "parts" and expressed strong negative reactions to the term "abortion." Though "spontaneous abortion" is a medically accurate term, the word "abortion" carries with it an array of sociopolitical connotations (Silverman \& Baglia, 2015). This, in addition to the moral undertones of mothers' failure to sustain the life of her child (Erviti, Castro, \& Collado, 2004; Hamama-Raz et al., 2010; Malacrida, 1999), creates difficult environments for women trying to cope with an unexpected loss of a child. It may be possible to develop a list of commonly used medical terminology in this situation and offer alternative words or ways to 
phrase procedures that is sensitive to the personal experience of each woman to help her feel less at fault for an event that was out of her control.

Our results suggest specific strategies and behavioral approaches and by incorporating not only the recommendations but also by using patients' voices with specific quotations in the training, we may increase empathy or at least draw attention to the needs of women during this traumatic experience. Klitzman (2006) suggested that using patient accounts in provider education may be a compelling way to increase empathy with doctors-in-training, and this study provides useful patient perspectives that could enhance training health care providers in delivering the bad news of a miscarriage. Other training models for teaching providers to deliver bad news in the OB/GYN context have been based on general approaches to bad news delivery (Karkowsky et al., 2016) or have adapted the six steps of the SPIKES protocol (i.e., Setting, Perception, Invitation, Knowledge, Empathy, and Strategy/Summary) (Marko et al., 2015), which was developed for oncology. Our study, however, outlines a set of communication practices specific to miscarriage. This is particularly important because too often communicating the news of a miscarriage is compared to delivering other "bad" diagnoses, such as cancer, which do not take into consideration the uniqueness of this ambiguous loss.

Our methodological approach to finding these recommendations was unique in that we were able to evaluate both the realism of using simulations with SPs as a training tool while also privileging the voices of women who have experienced miscarriage. This study design not only maximizes the power of qualitative research methods to explore complex topics and obtain information from individuals who are uniquely positioned to understand those topics, but it also creates a safe distance for patients to share because of their focus on others' similar experiences. By asking women to assess the video recordings and reflect on their own interactions with health 
care providers, our findings offer a robust understanding of bad news delivery during a miscarriage. Based on women's personal experiences and their evaluation of recorded interactions, our findings illustrate specific behaviors that are preferred (or not) in clinical communication about miscarriage.

\section{Limitations and Directions for Future Research}

The nature of our sample should be considered when translating the findings of this study into practice. Most of the women in our sample experienced the miscarriage of a desired pregnancy. Preferences of women coping with the loss of an undesired pregnancy could differ in important ways from our findings and should be explored in future research. In addition, our sample included an unusually large number of women who experienced multiples losses (Ford \& Schust, 2009). Although our analysis did not reveal discernible differences between these women and those who had experienced single losses, it is possible that women's preferences for communication might evolve over time if they confront multiple miscarriages.

This study reveals preferred communicative responses desired by women who have experienced miscarriage when communicating with a health provider during a traumatic event. We would be remiss, however, not to mention that although miscarriage is physically experienced by a woman carrying the child, her partner and/or other supportersare also likely affected by the delivery of bad news. As noted by Bute and Brann (2015), couples view a miscarriage as a shared but distinct experience and both members of the dyad are affected by the loss. Because partners' (commonly men's) needs are often overlooked during a miscarriage (Walker \& Walker, 2015), future research could also assess their preferences for learning about the bad news. This is particularly important as Fallowfield and Jenkins (2004) noted that not just 
patients but also relatives respond differently to how bad news is delivered, which may affect how they interpret the information and provide support to patients.

Our findings suggest that health care providers can engage in effective communication by following the practices offered by patients themselves. Learning effective communication strategies to deliver the bad news of miscarriage may also help providers in other types of pregnancy loss situations at different stages of a pregnancy. If providers learn how to empathically communicate the loss of a baby in the first trimester, they may be able to more effectively communicate the loss of a baby in later trimesters as well, which also warrants further exploration. Malacrida (1999) noted that providers diagnosing a late-term perinatal loss, particularly after an ultrasound similar to the scenario in this study, provided "blunt disclosures" about the death of the child and left women wondering what to do next. Ineffective communicative behaviors thus appear in all stages of pregnancy loss, but this may be rectified. Malacrida (1999) noted that the cost to train providers to communicate "humanely" is minimal, which is what this study supports doing - using the suggestions of women themselves to create a more humane conversation between patients and providers. 


\section{References}

American Pregnancy Association. (2017, May 2). Miscarriage. Retrieved from http://www.americanpregnancy.org/pregnancycomplications/miscarriage.html

Adolfsson, A., Larsson, P. G., Wijma, B., \& Bertero, C. (2004). Guilt and emptiness: Women's experiences of miscarriage. Health Care for Women International, 25, 543-560. doi:10.1080/07399330490444821

Bellhouse, C., Temple-Smith, M., Watson, S., \& Bilardi, J. (2018). “The loss was traumatic ... some healthcare providers added to that": Women's experiences of miscarriage. Women and Birth. Advance online publication. doi:10.1016/j.wombi.2018.06.006

Brann, M. (2015). Nine years later and still waiting: When health care providers' social support never arrives. In R. Silverman \& J. Baglia (Eds.), Pregnancy loss: A narrative collection (pp. 19-31). New York, NY: Peter Lang Publishing. doi:10.3726/978-1-4539-1384-0

Brann, M., \& Bute, J. J. (2017). Communicating to promote informed decisions in the context of early pregnancy loss. Patient Education and Counseling, 100, 226-2274. doi:10.1016/j.pec.2017.06.016

Brier, N. (2008). Grief following miscarriage: A comprehensive review of the literature. Journal of Women's Health, 17, 451-464. doi:10.1089/jwh.2007.0505

Bute, J. J., \& Brann, M. (2015). Co-ownership of private information in the miscarriage context. Journal of Applied Communication Research, 43, 23-43.

doi:10.1080/00909882.2014.982686

Davies, B., Steele, R., Krueger, G., Albersheim, S., Baird, J., Bifirie, M., ... Zhao, Y. (2017). Best practice in provider/parent interaction. Qualitative Health Research, 27, 406-420. doi: $10.1177 / 1049732316664712$ 
Erviti, J., Castro, R., \& Collado, A. (2004). Strategies used by low-income Mexican women to deal with miscarriage and "spontaneous" abortion. Qualitative Health Research, 14, 10581076. doi:10.1177/1049732304267693

Fallowfield, L., \& Jenkins, V. (2004). Communicating sad, bad, and difficult news in medicine. Lancet, 363, 312-319. doi:10.1016/S0140-6736(03)15392-5

Ford, H. B. (2009). Recurrent pregnancy loss: etiology, diagnosis, and therapy. Reviews in Obstetrics and Gynecology, 2(2), 76-83.

Frost, J., Bradley, H., Levitas, R., Smith, L., \& Garcia, J. (2007). The loss of possibility: Scientisation of death and the special case of early miscarriage. Sociology of Health and Illness, 29, 1003-1022. doi:10.1111/j.1467-9566.2007.01019.x

Gair, S. (2012). Feeling their stories: Contemplating empathy, insider/outsider positionings, and enriching qualitative research. Qualitative Health Research, 22, 134-143. doi: $10.1177 / 1049732311420580$

Hamama-Raz, Y., Hemmendinger, S., \& Buchbinder, E. (2010). The unifying difference: Dyadic coping with spontaneous abortion among religious Jewish couples. Qualitative Health Research, 20, 251-261. doi:10.1177/1049732309357054

Karkowsky, C. E., Landsberger, E. J., Bernstein, P. S., Dayal, A., Goffman, D., Madden, R., \& Chazotte, C. (2016). Breaking bad news in obstetrics: a randomized trial of simulation followed by debriefing or lecture. The Journal of Maternal-Fetal \& Neonatal Medicine, 29, 3717-3723. doi:10.3109/14767058.2016.1141888

Kemp, E. C., Floyd, M. R., McCord-Duncan, E., \& Lang, F. (2008). Patients prefer the method of "tell back-collaborative inquiry" to assess understanding of medical information. The Journal of the American Board of Family Medicine, 21, 24-30. 
doi:10.3122/jabfm.2008.01.070093

King, A., \& Hoppe, R. B. (2013). "Best practice" for patient-centered communication: A narrative review. Journal of Graduate Medical Education, 5, 385-393. doi:10.4300/JDME-D-13-00072.1

Klitzman, R. (2006). Improving education on doctor-patient relationships and communication: Lessons from doctors who become patients. Academic Medicine, 81, 447-453. doi:10.1097/01.ACM.0000222271.52588.01

Kushner, R. F., Zeiss, D. M., Feinglass, J. M., \& Yelen, M. (2014). An obesity educational intervention for medical students addressing weight bias and communication skills using standardized patients. BMC Medical Education, 14, 53-60. doi:10.1186/1472-6920-14-53

Malacrida, C. (1999). Complicating mourning: The social economy of perinatal death. Qualitative Health Research, 9, 504-519. doi:10.1177/104973299129122036

Marko, E. K., Buery-Joyner, S. D., Sheridan, M. J., Nieves, K., Khoury, A. N., \& Dalrymple, J. L. (2015). Structured Teaching of Early Pregnancy Loss Counseling. Obstetrics \& Gynecology, 126, 1S-6S. doi:10.1097/AOG.0000000000001015

Mast, M. S., Kindlimann, A., \& Langewitz, W. (2005). Recipients' perspective on breaking bad news: How you put it really makes a difference. Patient Education and Counseling, 58, 244-251. doi:10.1016/j.pec.2005.05.005

Morse, J. (2011). Hearing bad news. Journal of Medical Humanities, 32, 187-211. doi:10.1007/s10912-011-9138-4

Munoz Sastre, M. T., Sorum, P. C., \& Mullet, E. (2011). Breaking bad news: The patient's viewpoint. Health Communication, 26, 649-655. doi:10.1080/10410236.2011.561919 
Newble, D., 2004. Techniques for measuring clinical competence: objective structured clinical examinations. Medical Education, 38, 199-203. doi:10.1111/j.1365-2923.2004.01755.x

Olesen, M. L., Graungaard, A. H., \& Husted, G. R. (2014). Deciding treatment for miscarriageExperiences of women and health care professionals. Scandinavian Journal of Caring Sciences, 29, 386-394. doi:10.1111/scs.12175

Silverman, R. E., \& Baglia, J. (2015). Introduction: The politics of pregnancy loss. In R. E. Silverman \& J. Baglia (Eds.) Communicating pregnancy loss: Narrative as a method for change (pp. 1-16). New York, NY: Peter Lang Publishing, Inc. doi:10.3726/978-1-45391384-0

Sparks, L., Villagran, M. M., Parker-Raley, J, \& Cunningham, C. B. (2007). A patient-centered approach to breaking bad news: Communication guidelines for health care providers. Health Communication, 35, 177-196. doi:10.1080/00909880701262997

Street, Jr., R. L., \& De Haes, H. C. J. M. (2013). Designing a curriculum for communication skills training from a theory and evidence-based perspective. Patient Education and Counseling, 93, 27-33. doi:10.1016/j.pec.2013.06.012

Swanson, K. M. (2000). Predicting depressive symptoms after miscarriage: A path analysis based on the Lazarus paradigm. Journal of Women's Health \& Gender-Based Medicine, 9, 191-206. doi:10.1089/152460900318696

Tracy, S. J. (2013). Qualitative research methods: Collecting evidence, crafting analysis, communicating impact. Hoboken, NJ: Wiley-Blackwell.

Walker, J. L. G., \& Walker, B. M. (2015). Unscripted loss: A hesitant narrative of a reconstructed family. In R. E. Silverman \& J. Baglia (Eds.) Communicating pregnancy 
loss: Narrative as a method for change (pp. 59-70). New York, NY: Peter Lang Publishing, Inc. doi:10.3726/978-1-4539-1384-0

Wallace, R. R., Goodman, S., Freedman, L. R., Dalton, V. K., \& Harris, L. H. (2010). Counseling women with early pregnancy failure: utilizing evidence, preserving preference. Patient Education and Counseling, 81, 454-461.

doi:10.1016/j.pec.2010.10.031 